\title{
Analisis Perbandingan Performansi MIPv6 (Mobile Internet Protocol v6) dan HMIPv6 (Hierarchical Mobile Internet Protocol v6) pada VANET (Vehicular Ad- Hoc Network)
}

\author{
Iqsyahiro Kresna A. ${ }^{1}$, Yoso Adi Setyoko², Aditya Wijayanto ${ }^{3}$ \\ hiro@ittelkom-pwt.ac.id ${ }^{1}$, yoso@ittelkom-pwt.ac.id ${ }^{2}$, aditya.wijayanto@ittelkom-pwt.ac.id ${ }^{3}$ \\ ${ }^{1}$ S1 Informatika, Fakultas Teknologi Industri dan Informatika, IT Telkom Purwokerto \\ ${ }^{2}$ S1 Informatika, Fakultas Teknologi Industri dan Informatika, IT Telkom Purwokerto \\ ${ }^{3}$ S1 Rekayasa Perangkat Lunak, Fakultas Teknologi Industri dan Informatika, IT Telkom \\ Purwokerto
}

Diterima: 11 Februari 2019 | Direvisi: 03 Mei 2019 | Disetujui: 17 Juni 2019

(C) 2019 Program Studi Sistem Informasi Fakultas Sains dan Teknologi,

Universitas Islam Negeri Raden Fatah Palembang, Indonesia

\begin{abstract}
Abstrak: VANET (Vehicular Ad-Hoc Network) adalah bentuk khusus dari MANET (Mobile Ad-Hoc Network). VANET (Vehicular Ad-Hoc Network) adalah jaringan yang terdiri dari kumpulan node mobile nirkabel yang berkomunikasi satu sama lain tanpa infrastruktur yang tetap. Pergerakan MN (Mobile Node) pada VANET sangat tinggi dan menyebabkan IP Address pada MN sering berubah. Berdasarkan kondisi jaringan yang berubah, koneksi yang terjadi antara MN menjadi terganggu dan terputus selama beberapa detik. Selain itu, menyebabkan delay yang besar dan throughput yang lebih kecil dengan paket loss tinggi jika di suatu daerah jumlah MN meningkat secara signifikan. Dalam simulasi ini diukur kinerja antara jaringan Mobile IPv6 (MIPv6) dan Hierarchical Mobile IPv6 (HMIPv6) menggunakan agen transport UDP dengan beberapa ukuran paket data CBR. Berdasarkan parameter utama dalam menentukan kualitas jaringan, akan dibandingkan dan diperoleh nilai dari handover latensi, dengan mengukur packet loss, throughput, dan delay. Berdasarkan hasil studi literatur, dapat disimpulkan bahwa kinerja jaringan HMIPv6 lebih baik daripada MIPv6 karena HMIPv6 memiliki paket loss dan delay yang lebih kecil dan throughput yang lebih besar dibandingkan dengan MIPv6.
\end{abstract}

Kata Kunci: VANET, HMIPv6, MIPv6

\begin{abstract}
VANET (Vehicular Ad-Hoc Network) is a special form of MANET (Mobile Ad-Hoc Network). VANET (Vehicular Ad-Hoc Network) is a network consisting of a collection of wireless mobile nodes that communicate with each other without a fixed infrastructure. The movement of MN (Mobile Node) on VANET is very high and causes IP Address on MN to change frequently. Based on the changing network conditions, the connection that occurs between $M N$ becomes disrupted and disconnected for several seconds. In addition, large delays and smaller throughput with high packet loss if in an area the number of MN increases significantly. In this simulation performance is measured between Mobile IPv6 (MIPv6) and Hierarchical Mobile IPv6 (HMIPv6) networks using UDP transport agents with several CBR data packet sizes. Based on the main parameters in determining network quality, it will be compared and obtained the value of handover latency, by measuring packet loss, throughput, and delay. Based on the results of the literature study, it can be concluded that network performance of HMIPv6 has better than MIPv6 because HMIPv6 has smaller packet loss and delay and greater throughput compared to MIPv6.
\end{abstract}

Keywords: VANET, HMIPv6, MIPv6

\section{PENDAHULUAN}

Penggunaan jaringan wireless sebagai salah satu media komunikasi data semakin berkembang dengan pengaplikasiannya yang semakin beragam. Selain itu, infrastruktur 
jaringan untuk mengakses jaringan wireless pun sudah mulai stabil dan semakin bertambah jumlahnya. Seiring dengan bertambahnya jumlah node yang terhubung, maka terdapat lonjakan nilai dari delay dan packet loss, serta terjadi penurunan dari nilai throughput dari protokol routing yang digunakan.

VANET merupakan salah satu solusi untuk wireless mobile network yang sudah diterapkan oleh negara-negara di Eropa dan Amerika Serikat yang berkecimpung dalam dunia otomotif. VANET diharapkan dapat mengoptimalkan keamanan dan kenyamanan pengendara kendaraan.

MIP (Mobile Internet Protocol) mendukung mobilitas user untuk menggunakan sekurang-kurangnya 2 Internet Protocol (IP) address yaitu home address yang merupakan fixed address dan CoA (care-of address) berupa IP address temporary yang berubah sesuai dengan IP subnet di jaringan lokasi MN berada pada protokol MIPv6. Banyaknya MN yang terhubung menyebabkan packet loss dan delay yang besar dan handover latency yang tinggi dalam jaringan. Alternatif solusi untuk menyelesaikan masalah ini adalah dengan menggunakan protocol HMIPv6. HMIPv6 mempunyai kemampuan untuk mengelola routing perubahan dalam domain mereka dengan menggunakan MAP (Mobility Anchor Points) pada jaringan asing sehingga dapat meningkatkan kecepatan handover latency. Node koresponden berisi alamat MN atau alamat hirarki (Cetin \& Cetin, 2015).

\section{METODOLOGI PENELITIAN}

\subsection{VANET (Vehicular Ad-Hoc Network)}

VANET (Vehicular Ad-Hoc Network) adalah bentuk khusus dari MANET (Mobile AdHoc Network). Terdapat 3 jenis hubungan komunikasi dengan menggunakan jaringan nirkabel pada VANET. Pertama adalah V2V (Vehicle to Vehicle) yaitu komunikasi antar dua MN atau lebih pada suatu lintasan. Kedua adalah V2I (Vehicle to Road side Infrastructure) yang memungkinkan sebuah MN untuk berkomunikasi dengan infrastruktur yang terdapat pada lintasan. Ketiga adalah Hybrid Architecture yaitu merupakan penggabungan hubungan V2V dan V2I (Rasheed, Gillani, Ajmal, \& Qayyum, 2017).

VANET memiliki arsitektur jaringan yang dapat diklasifikasikan ke dalam tiga kategori: pure cellular/ WLAN (Wireless Local Area Network), pure ad-hoc, dan hybrid (Ghafoor, Mohammed, Lloret, Bakar, \& Zainuddin, 2018).

VANET mempunyai beberapa karakteristik unik yang membedakannya dengan MANET. Karakteristik tersebut adalah Dynamic Topology, Frequent Disconnected Network, Mobility Modeling, Power Source, dan Communication Environment (Paul B, Ibrahim Md, \& Bikas, 2011).

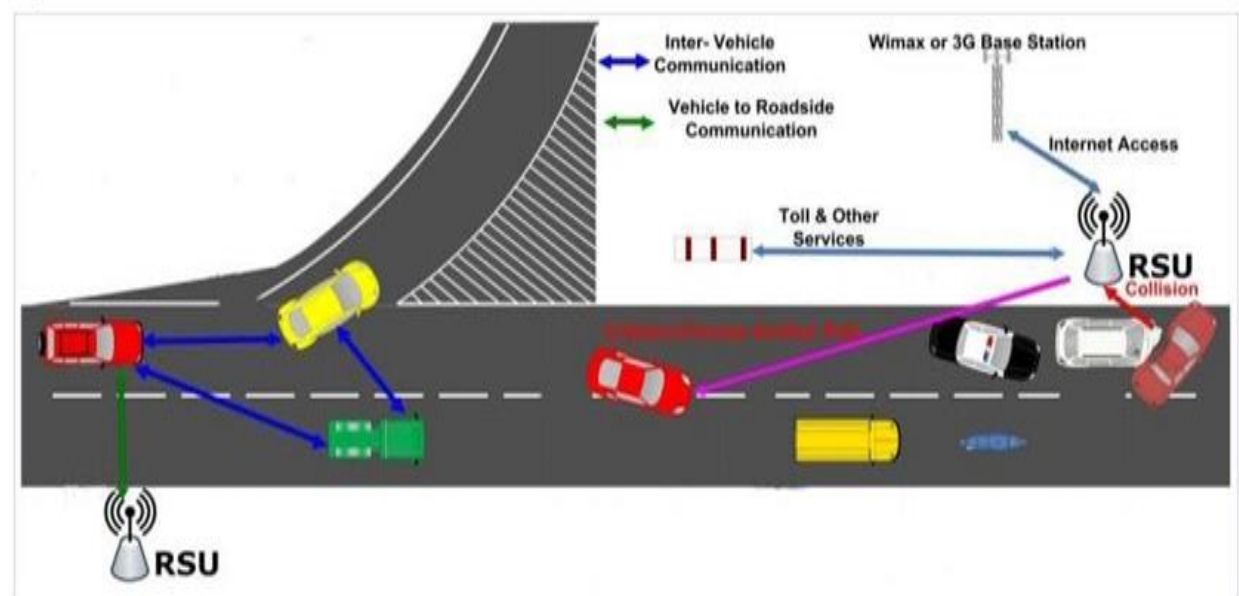

Gambar 1. Penerapan Aplikasi VANET

Sumber: (Paul B et al., 2011) 


\subsection{MIPv6 (Mobile Internet Protocol v6)}

MIPv6 (Mobile Internet Protocol v6) adalah protokol yang dikembangkan sebagai bagian dari IPv6 untuk mendukung koneksi bergerak. MIPv6 merupakan pengembangan dari standar IP IETF Mobile (RFC 2002) yang dirancang untuk mengotentikasi perangkat mobile dengan menggunakan alamat IPv6.

MIPv6 memungkinkan MN untuk mempertahankan koneksi yang nyata ketika bergerak dari satu jaringan ke jaringan yang lain. Setiap perangkat diidentifikasi berdasarkan alamat rumahnya meskipun mungkin terhubung ke jaringan lain. Ketika terhubung melalui jaringan asing, perangkat mobile mengirimkan informasi lokasi untuk home agent, memotong paket yang ditujukan untuk perangkat dan tunnel mereka ke lokasi saat ini (Meng, Da, \& Wang, 2017).

\subsection{HMIPv6 (Hierarchical Mobile IPv6)}

HMIPv6 (Hierarchical Mobile IPv6) adalah peningkatan yang diusulkan dari (Mobile Internet Protocol v6) yang dirancang untuk mengurangi jumlah sinyal yang diperlukan dan untuk meningkatkan kecepatan handoff untuk koneksi bergerak. HMIPv6 adalah standar yang diusulkan dari IETF (Internet Engineering Task Force). MIPv6 mendefinisikan sarana pengelolaan global (antara-situs) mobilitas, tetapi tidak menangani masalah lokal (dalamsitus) mobilitas secara terpisah. Sebaliknya, menggunakan mekanisme yang sama dalam kedua kasus, yang merupakan inefisiensi penggunaan sumber daya dalam hal mobilitas lokal. HMIPv6 menambah tingkat lain, dibangun pada MIPv6 yang memisahkan lokal dari mobilitas global. Mobilitas global dalam HMIPv6 dikelola oleh protocol MIPv6, sedangkan handoffs local dikelola secara lokal.

Sebuah perangkat baru di HMIPv6 disebut MAP (Mobile Anchor Point) yang berfungsi sebagai entitas lokal untuk membantu dalam handoffs mobile. MAP yang menggantikan foreign agent $\mathrm{MIPv} 4$ ini dapat ditemukan di mana saja dalam hirarki router. Berbeda dengan foreign agent, tidak ada persyaratan untuk MAP untuk berada pada subnet masing-masing. MAP membantu untuk mengurangi handoff terkait latency.

MN pada HMIPv6 mengirimkan update lokasi ke setiap node yang sesuai ketika MN berpindah lokasi dan pada interval berselang sebaliknya. Dengan memisahkan mobilitas global dan lokal, HMIPv6 memungkinkan untuk menghadapi situasi secara lebih baik dan tepat (Kim, 2018).

\subsection{Parameter Pengujian}

Parameter uji merupakan bagian dari penelitian yang tujuannya untuk melihat hasil performansi dari setiap protokol yang digunakan. Parameter yang digunakan pada penelitian ini adalah packet loss, throughput dan delay.

\subsubsection{Packet Loss}

Paket loss dapat disebabkan oleh sejumlah faktor yang mencakup penurunan sinyal dalam media jaringan, melebihi batas saturasi jaringan, paket corrupt yang menolak untuk transit, dan kesalahan hardware jaringan. Beberapa jaringan transport protocol seperti TCP menyediakan pengiriman paket yang dapat dipercaya. Dalam hal kerugian paket, penerima akan meminta retransmission atau pengiriman secara otomatis yang mengirim ulang walaupun segmen sudah tidak diakui. Meskipun TCP dapat memulihkan dari kerugian paket, retransmitting paket yang hilang menyebabkan throughput yang menyebabkan koneksi dapat berkurang. Jika suatu paket yang dipancarkan hilang di dalam TCP, makan akan dilakukan pengiriman ulang bersama dengan tiap-tiap paket yang telah dikirim setelahnya. Retransmission ini menyebabkan koneksi menjadi lambat (Larry L. Peterson, 2014).

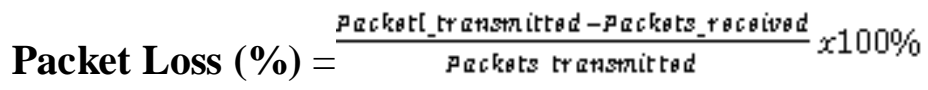




\subsubsection{Throughput}

Throughput adalah kemampuan sebenarnya suatu jaringan dalam melakukan pengiriman data. Biasanya throughput selalu dikaitkan dengan bandwidth. Karena throughput memang bisa disebut juga dengan bandwidth dalam kondisi yang sebenarnya. Bandwidth lebih bersifat tetap sementara throughput sifatnya adalah dinamis tergantung trafik yang sedang terjadi (Larry L. Peterson, 2014).

$$
\text { Throughput (bps) }=\frac{\text { jumlah data yang dikirim }}{\text { waktu pengiriman data }}
$$

\subsubsection{Delay}

Delay adalah total waktu yang diperlukan oleh suatu paket data yang berasal dari source node hingga mencapai destination node. Delay secara tidak langsung berhubungan dengan kecepatan transfer data suatu jaringan (Larry L. Peterson, 2014).

$$
\text { Delay }(\mathrm{ms})=\frac{\operatorname{RTD}(\text { Round Trip Delay }}{2}
$$

\subsection{Analisis Kebutuhan Sistem}

Pada penelitian ini, dibangun simulasi pada aplikasi NS-2 (Network Simulator 2) untuk penerapan routing protocol MIPv6 dan HMIPv6 pada komunikasi V2I (vehicle-toinfrastructure). Simulasi ini digunakan untuk menguji dan menganalisis performansi jaringan wireless access in vehicular network berupa throughput, delay dan packet loss yang mempengaruhi konektivitas pada saat terjadi handovers pada sistem yang dibangun. Secara garis besar, arsitektur yang dibangun ditunjukkan pada Gambar 2.

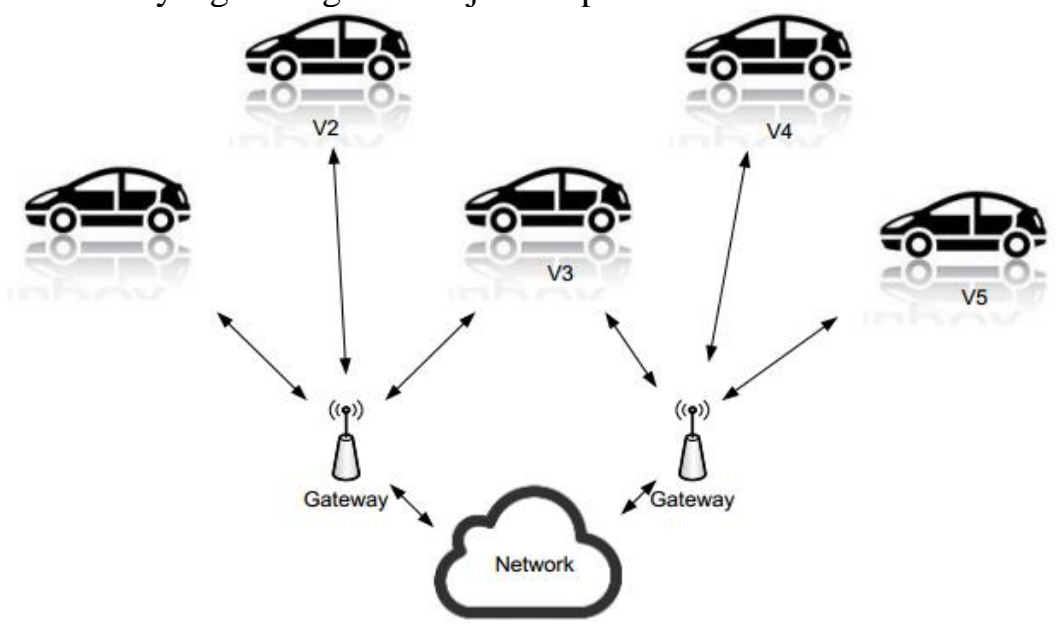

Gambar 2. Arsitektur VANET

\subsubsection{Parameter Spesifikasi Protokol MIPv6 pada NS-2}

Nilai parameter yang digunakan untuk protokol MIPv6 agar simulasi dapat berjalan dengan maksimal dapat dilihat pada Tabel 1. 
Tabel 1. Parameter MIPv6 pada NS-2

\begin{tabular}{|l|c|}
\hline \multicolumn{2}{|c|}{ MIPv6 } \\
\hline Parameter & Setting \\
\hline Mobility model & M-Grid \\
\hline Data Transfer Protocol & UDP \\
\hline Bitrate & 512 kb \\
\hline Simulation time & 60 seconds \\
\hline
\end{tabular}

\subsection{Desain dan Skenario Simulasi}

Desain simulasi dilakukan sebelum dibuat pada simulator NS-2. Tahap ini dilakukan agar pada saat simulasi layanan komunikasi untuk vehicle-to-infrastructure dapat merepresentasikan penerapan untuk dunia nyata. Simulasi yang baik adalah apabila hasil dari simulasi hasilnya sedekat mungkin dengan implementasi di dunia nyata.

Tujuan dari simulasi ini adalah untuk menganalisis parameter dari layanan pada jaringan VANET yang di tempatkan pada jalan bebas hambatan, problem utama yang dapat membatasi pengembangan layanan ini adalah packet loss yang terjadi karena pengaruh dari banyaknya handover yang terjadi pada saat pengiriman paket data antar node. Untuk mengukur performansi-nya dibuat 3 skenario untuk tiap routing protokol.

Pada simulasi ini dirancang 6 skenario simulasi yang memiliki kerapatan node yang berbeda-beda.

Tabel 2. Skenario Simulasi MIP dan HMIP

\begin{tabular}{|c|l|c|c|}
\hline Simulasi ke- & Routing Protokol & $\begin{array}{c}\text { Jumlah Node } \\
\text { (MN) }\end{array}$ & $\begin{array}{c}\text { Kecepatan } \\
\text { (KM/jam) }\end{array}$ \\
\hline 1 & MIP & $\mathbf{1 6}$ & $\mathbf{8 0}$ \\
\hline 2 & MIP & 32 & $\mathbf{8 0}$ \\
\hline 3 & MIP & 48 & $\mathbf{8 0}$ \\
\hline 4 & HMIP & $\mathbf{1 6}$ & $\mathbf{8 0}$ \\
\hline 5 & HMIP & 32 & $\mathbf{8 0}$ \\
\hline 6 & HMIP & $\mathbf{4 8}$ & $\mathbf{8 0}$ \\
\hline
\end{tabular}

Pada simulasi ini node akan bergerak pada kecepatan di atas tersebut pada jalan tol bebas hambatan dari home agent menuju foreign agent 1 dan seterusnya sampai foreign agent terakhir. Pengambilan data yang mengimplementasikan pemodelan jaringan dan wireless access point serta analisisnya terhadap throughput, delay dan packet loss dijelaskan pada Gambar 3.

\subsubsection{Topologi Jaringan}

Pada penelitian ini menggunakan tiga buah perangkat utama, yaitu router, wireless mobile, dan access point. Berikut adalah gambaran dari topologi jaringan pada simulasi ini baik pada skenario pertama, kedua dan ketiga. Topologi ini dibuat sesuai dengan kondisi pada jalur lintas cepat/highway di mana PAR (Previous Access Router) dan NAR (New Access Router) diletakkan di ujung jalan yang posisinya lebih dekat dengan MN.

Topologi ini dibuat sesuai dengan kondisi pada jalur lintas cepat/highway di mana PAR dan NAR diletakkan di ujung jalan yang posisinya lebih dekat dengan MN. Pada Tabel 3 dijelaskan penomoran node dari masing masing node yang ada pada topologi jaringan di Gambar 4. 


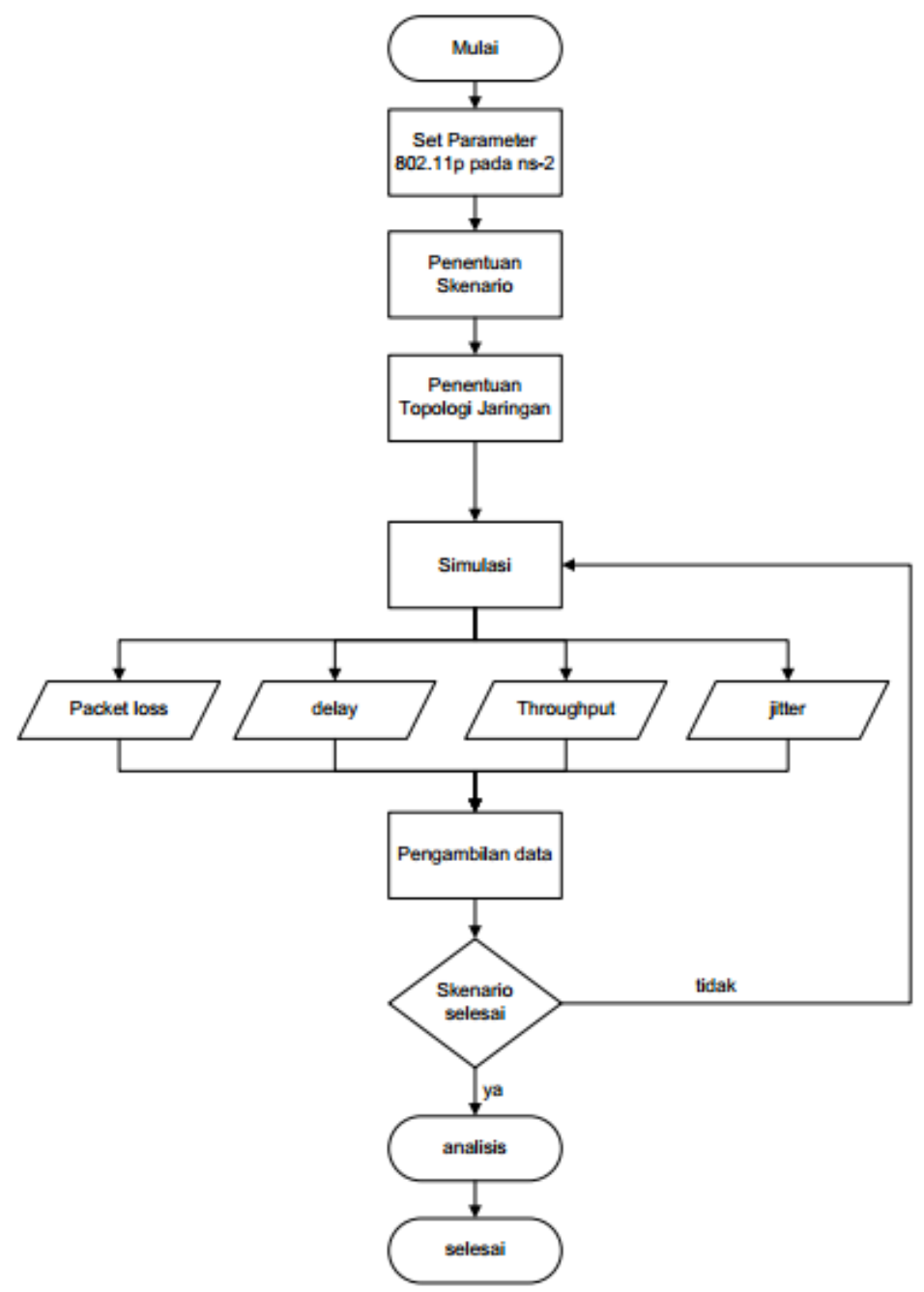

Gambar 3. Flowchart Alur Penelitian

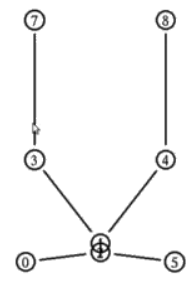

Gambar 4. Topologi Jaringan

Tabel 3 Penomoran Node pada Topologi Jaringan

\begin{tabular}{|l|c|c|c|c|c|c|c|c|}
\hline No. Node & 0 & 1 & 2 & 3 & 4 & 5 & 7 & 8 \\
\hline Jenis Node & CH & MAP & N1 & N2 & N3 & HA & PAR & NAR \\
\hline
\end{tabular}

\subsubsection{Implementasi}

Implementasi simulasi akan dimodelkan menggunakan Model Konseptual Simulasi. Terdapat tiga elemen utama pada model ini yaitu input, control, dan output. Pada tahap ini, input simulasi berupa file pengaturan parameter simulasi baik throughput, delay, maupun packet loss akan dihitung berdasarkan informasi yang diterima dari tracing file ini. Output 
simulasi berupa trace file yang mencatat seluruh kejadian yang terjadi selama simulasi berlangsung.

\subsubsection{Pengambilan Data Simulasi}

Trace file pada NS-2 tersusun dalam format yang sudah ditentukan. Proses parsing dapat dilakukan pada trace file untuk mengambil data yang diperlukan untuk perhitungan parameter. Trace file berisi catatan seluruh kejadian yang dialami oleh suatu paket simulasi. Pembuatan trace file dilakukan dengan memanggil objek trace pada library, biasanya keluaran berupa .tr (trace file). Adapun untuk menampilkan suatu model simulasi juga dilakukan pembuatan animator file yang berformat nam (Network animator file).

\subsubsection{Perancangan Uji Skenario}

Skenario pengujian berfungsi sebagai strategi pengujian yang diperlukan agar pengujian dapat mencapai tujuan yang diinginkan. Pada penelitian ini, terdapat 6 skenario pengujian yang disimulasikan untuk mencapai tujuan pengujian. Setiap skenario pengujian memodelkan topologi jaringan yang sama dengan parameter jumlah node pada protokol yang berbeda. Pada skenario simulasi ini, model topologi jaringan yang dibuat untuk mensimulasikan hubungan antara mobile node dengan wireless access point yang berhubungan dengan server melalui router. Pada setiap skenario masing- masing akan dihitung nilai throughput, delay dan packet loss untuk nantinya akan dijadikan sebagai bahan analisis dari tujuan pembuatan penelitian ini.

Pada animator untuk aplikasi NS-2, terdapat 2 skenario untuk masing-masing routing protokol. Skenario awal untuk kedua routing protokol yang akan diuji yaitu dengan menggunakan $16 \mathrm{MN}$. Diasumsikan mobil bergerak pada batas terendah di jalanan bebas hambatan yaitu $80 \mathrm{Km} / \mathrm{Jam}$ seperti pada Gambar 5 .

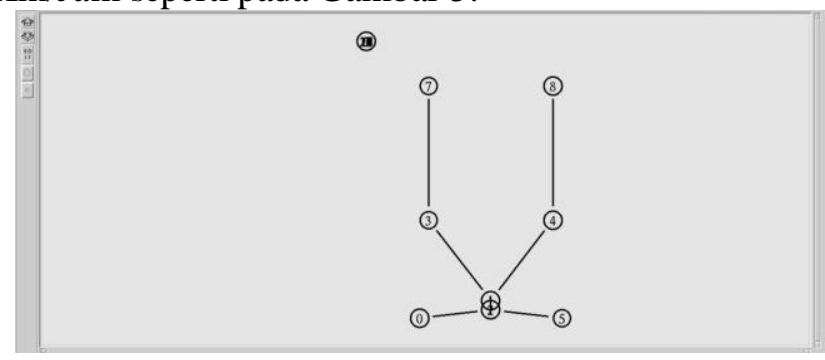

\section{Gambar 5. Skenario Pertama Pada Kedua Routing Protocol}

Skenario kedua yaitu dengan menggunakan $32 \mathrm{MN}$. Diasumsikan mobil bergerak pada batas terendah di jalanan bebas hambatan yaitu $80 \mathrm{Km} / \mathrm{Jam}$ seperti pada Gambar 6 .

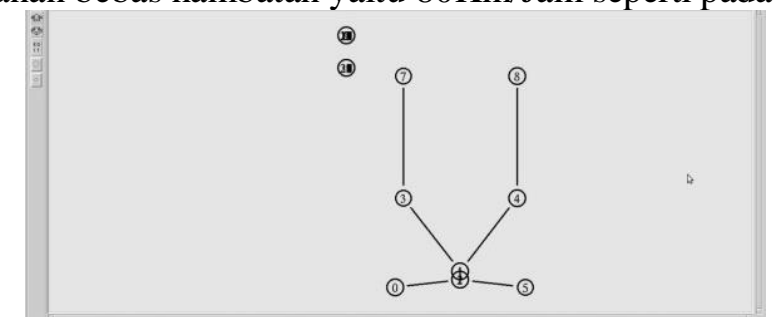

\section{Gambar 6. Skenario Kedua Pada Kedua Routing Protocol}

Skenario ketiga yaitu dengan menggunakan $16 \mathrm{MN}$. Diasumsikan mobil bergerak pada batas terendah di jalanan bebas hambatan yaitu $80 \mathrm{Km} / \mathrm{Jam}$ seperti pada Gambar 7 . 


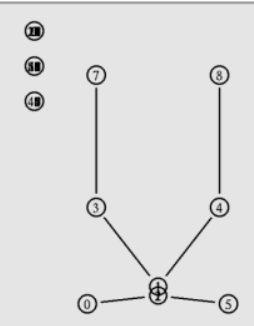

\section{Gambar 7. Skenario Ketiga Pada Kedua Routing Protocol}

\section{HASIL DAN PEMBAHASAN}

\subsection{Analisis Throughput}

Pada perbandingan throughput ini HMIP lebih unggul bila dibandingkan dengan MIP. Hal ini dikarenakan pada protocol HMIP terdapat priority pada HA (Home Agent), NAR dan PAR. Dimana MN $\Leftrightarrow$ MAP $\Leftrightarrow$ HA. Sehingga MN yang bergerak akan dianggap sama dengan HA dan mempunyai prioritas lebih besar dibandingkan PAR dan NAR. Hasil analisis throughput dapat dilihat pada Gambar 8.

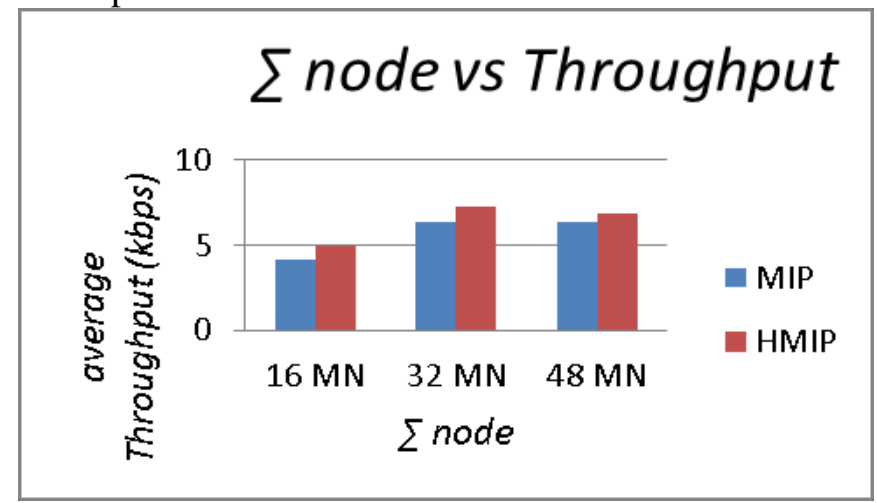

Gambar 8. Hasil Analisis Throughput

\subsection{Analisis Packet Loss}

Pada perbandingan packet loss ini HMIP lebih unggul bila dibandingkan dengan MIP. Hal ini dikarenakan sebuah router yang berada pada jaringan yang dikunjungi MN digunakan oleh MN sebagai HA lokal. Saat MN melakukan handoff antara dua access point pada domain MAP yang sama hanya menginformasikan MAP, sehingga beban persinyalan berkurang ketika MN merubah attachment point dalam domain yang sama dan packet loss bisa dikurangi selama handoff intra-domain.

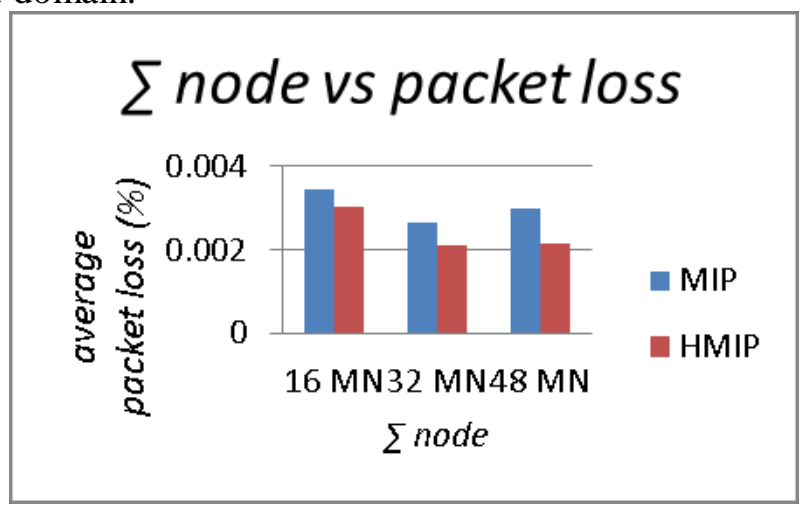

Gambar 9. Hasil Analisis Packet Loss 


\subsection{Analisis Packet Delay}

Pada perbandingan delay ini HMIP lebih unggul bila dibandingkan dengan MIP. Hal ini dikarenakan karena sebuah node baru di HMIPv6 disebut MAP berfungsi sebagai entitas lokal untuk membantu dalam handoffs mobile. MAP membantu mengurangi handoff terkait latency karena MAP lokal dapat diperbarui lebih cepat daripada HA.

Sedangkan pada MIPv6, MN mengirimkan lokasi terbaru ke setiap node setiap kali perubahan lokasi terjadi, dan pada interval berselang sebaliknya. Hal ini menggunakan banyak sinyal dan pengolahan, serta membutuhkan banyak sumber daya.

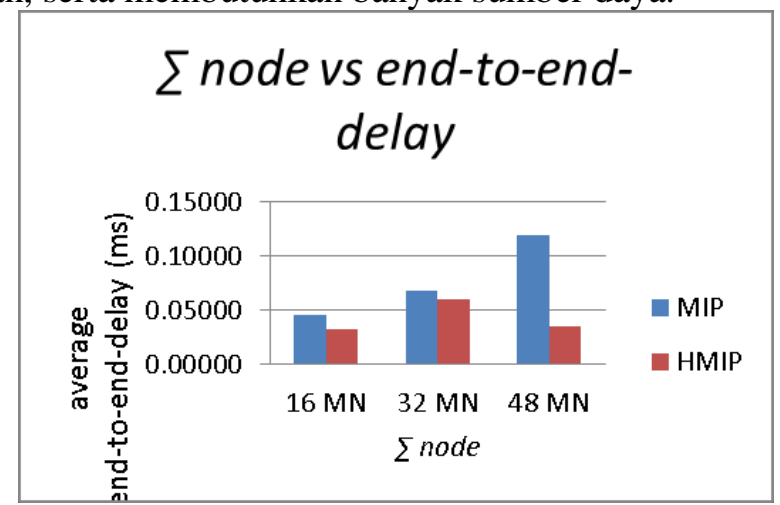

Gambar 10. Hasil Analisis Delay

\section{KESIMPULAN}

Berdasarkan tujuan serta hasil dari pengujian dan analisis yang telah dilakukan pada penggunaan MIPv6 dan HMIPv6, maka dapat diambil beberapa kesimpulan sebagai berikut:

1. Pada skenario highway, HMIPv6 lebih baik dari pada MIPv6. Karena aktivitas routing lebih sedikit. Keunggulan terletak pada throughput, delay, dan packet loss.

2. Penggunaan Routing Protokol pada $M I P v 6$ dan $H M I P v 6$ dapat diterapkan pada kondisi tertentu, terutama pada jalan bebas hambatan.

3. Pada parameter delay memang membutuhkan penyempurnaan, karena masih cukup besar. Untuk packet loss sudah cukup bagus karena kurang dari 1\%, namun masih bisa diterima pada jaringan VANET, karena batas packet loss untuk VANET adalah $20 \%$.

\section{DAFTAR RUJUKAN}

Cetin, G., \& Cetin, A. (2015). The Analysis Of Layer-2 Handover Performance For Mobile Ipv6 Using Omnet ++ Simulation Tool. Mugla Journal of Science and Technology, 1(1), $34-38$.

Ghafoor, K. Z., Mohammed, M. A., Lloret, J., Bakar, K. A., \& Zainuddin, Z. M. (2018). Routing Protocols in Vehicular Ad hoc Networks: Survey and Research Challenges. International Journal of Scientific Research in Computer Science, Engineering and Information Technology, 3(7), 39.

Kim, P. S. (2018). An Optimized Reactive Fast Inter-MAP Handover for HMIPv6 to Minimize Packet Loss. International Journal of Applied Engineering Research, 13(2), 1456-1459.

Larry L. Peterson, B. S. D. (2014). Computer Networks: A Systems Approach (4th Editio).

Morgan Kaufmann Publishers. 
Meng, R., Da, B., \& Wang, C. (2017). IP mobility enhancements for MIPv6 and PMIPv6. 2017 10th International Conference on Mobile Computing and Ubiquitous Network (ICMU 2017), 2017-Janua(156), 1-6.

Paul B, Ibrahim Md, \& Bikas, A. N. (2011). Article: VANET Routing Protocols: Pros and Cons. International Journal of Computer Applications, 20(3), 28-34.

Rasheed, A., Gillani, S., Ajmal, S., \& Qayyum, A. (2017). Vehicular Ad Hoc Network (VANET): A Survey, Challenges, and Applications. In A. Laouiti, A. Qayyum, \& M. N. Mohamad Saad (Eds.), Vehicular Ad-Hoc Networks for Smart Cities (pp. 39-51). Singapore: Springer Singapore. 